\title{
JUAN RULFO: EL ESTATUTO ONTOLÓGICO DE LA VIOLENCIA
}

\author{
Juan Rulfo: The ontological status of violence
}

\author{
Claudio César Calabrese* \\ Ethel Junco**
}

\begin{abstract}
RESUMEN
Proponemos una exploración de los niveles de violencia en las obras de Rulfo, detenida en los vínculos familiares (padre-madre-hijo), en la comunidad y en sus autoridades (pueblo, vecinos, instituciones). La violencia, concepto irracional y contrario a la civilización, se comporta en la cosmovisión de Rulfo como descriptor de un modo del orden que la convierte en natural. A través de una lectura descriptivo-analítica, para pasar a la interpretación simbólica, destacamos la acción constante de un tipo de violencia inmanente que no se somete al enunciado de la idea ilustrada de justicia. El discurso crítico de la literatura declara un determinismo pre-histórico que invalida la historia oficial.
\end{abstract}

Palabras clave: Rulfo, discurso crítico, violencia, orden natural.

\begin{abstract}
We propose an exploration of the levels of violence in the pieces of Rulfo, detained in the family ties (father-mother-son), in the community and in their authorities (people, neighbors, institutions). Violence, an irrational and anti-civilization concept, behaves in the worldview's Rulfo as a descriptor of a mode of order that makes it natural.
\end{abstract}

\footnotetext{
* Universidad Panamericana, Campus Aguascalientes, Departamento de Humanidades. Aguascalientes, México. Correo electrónico: ccalabrese@up.edu.mx

** Universidad Panamericana, Campus Aguascalientes, Departamento de Humanidades. Aguascalientes, México. Correo electrónico: ejunco@up.edu.mx
}

Artículo recibido el 26 de enero de 2017. Aprobado el 22 de enero de 2018. 
Through a descriptive-analytical reading, to move to the symbolic interpretation, we distinguish the constant action of a type of immanent violence that does not submit to the statement of the enlightened idea of justice. The critical discourse of literature declares a pre-historical determinism that invalidates the official story.

Keywords: Rulfo, critical discourse, violence, natural order.

\section{Violencia y vida}

No todo lo que acontece en el universo de Rulfo es razonable; acaso puede parecer primitivo, ridículo, incluso pre-desarrollado. Leído desde la Modernidad -desde la misma Modernidad cronológica en la que fue escrito- se disocia de sus procesos de modernización, marcha en paralelo. Al referirnos al concepto histórico, asumimos los presupuestos críticos de la Escuela de Frankfurt, en tanto señala a la razón instrumental y su homogeneización de las formas culturales como causa de la destrucción del individuo y la inducción a un "nuevo género de barbarie" (Horkheimer, 1969: 82).

Si los relatos fuesen un acertijo cuya resolución pidiera la intervención del lector, este bien podría solucionarlos con recursos sensatos de su mundo civilizado: oportunidades laborales en Es que somos muy pobres o Paso del Norte ${ }^{1}$, cárcel para los protagonistas de El hombre o de Diles que no me maten, educación digna para los jóvenes de La noche que lo dejaron solo o No oyes ladrar los perros, justicia social para los hombres en El llano en llamas, recursos del gobierno para el pueblo de El día del derrumbe o para los desamparados de Nos han dado la tierra, terapias adecuadas para los culpables y los inocentes de Talpa o de Macario. Para cualquier hijo del optimismo ilustrado habría un recurso y, como consecuencia, una resolución, pues todos esos hombres y mujeres tienen derechos y se ha predicado que hay un orden

\footnotetext{
${ }^{1}$ Las ediciones de las fuentes que serán citadas en todo el artículo son, para los cuentos: Rulfo, Juan. $E l$ llano en llamas. México: Ed. RM, 2005 y para la novela: Rulfo, Juan. Pedro Páramo. México: Ed. RM., 2005. Citaremos respectivamente: El llano y PP.
} 
social que debe cumplirlos. Pero el mito del progreso y su mejoría social, eje de la crítica frankfurtiana, queda expuesto con escepticismo ante los resultados de una supuesta articulación racional (Cruz Rivero, 1999: 102).

Las realidades de los personajes de Rulfo no se explican por la lógica consensuada del mundo moderno, aunque coexistan con él. Al decir de Girard: "El racionalismo apenas se plantea preguntas sobre unas costumbres que le parecen tanto más transparentes en la misma medida en que no se les atribuye más sentido que el ridículo" (2005: 131). A simple vista es incomprensible que la violencia sea ámbito de supervivencia, pues el mismo enunciado es contradictorio. No obstante, así acontece en los relatos que nos ocupan. Rulfo se independiza de un modo de contar la historia ligado a condicionantes de grupos de poder, como se impone desde hace más de cinco siglos en tierras americanas (Lara, 2013: 139).

Partimos de dos premisas que sugiere la fuente: en primer término, en la obra de Rulfo se expone una cosmogonía que, aunque trabaja desde materiales históricos, no se demora en ellos como objeto único de análisis; es decir, no pretende hablar a la historia ni advertir al hombre que la recorre. De ahí, la necesidad de la repetición -instancia propia del mito- que afianza lo que se configura en el tiempo. El tiempo no alcanza ni para vivir ni para ejemplificar y, menos aún, para que quede claro lo vivido. Rulfo propone el ciclo de la reiteración mítica para el intento de "decir" lo que es preexistente a la historia y que se expresará en la acción política. Aquí aplicamos la noción de mito en relación negativa con la política, siguiendo la reflexión de W. Benjamin (2009: 443-449). Para el autor hay una violencia mítica asociada al destino, con su componente de culpa y sanción, que en el mundo contemporáneo se reasume en las formas del estado y del orden jurídico, aptas para subordinar los modelos sociales. En esa línea, Rulfo muestra que la ley no es garantía de ecuanimidad, sino solo imposición de otra violencia sobre la vida.

En segundo término, la violencia es la atmósfera natural de los hombres 
y sus circunstancias, es el modo de ser de los acontecimientos. Si se extrajera de la coyuntura de los hechos -violencia explícita o implícita, física o psicológicacaería el fundamento del relato. En ella se unen los argumentos, eslabones de un mismo principio proteico que confirma su fatalismo: la violencia como una deidad cósmica, por encima de adoradores y detractores, de la cual nadie se exime, causa de vida y de muerte, generadora de víctimas que mutan en victimarios y viceversa. La historia personal del autor está signada por hechos de violencia, que se ven trasladados a sus escenarios y a la determinación trágica de los personajes (Chang Rodríguez-Piler, 2015: 420-421).

Con la premisa de que Rulfo ata violencia y vida, contrarios indispensables al cumplimiento de cierto orden, abordaremos el discurso literario como trama invertida de un concepto de civilización que neutraliza la lógica de la violencia y la reconduce en formatos ilustrados (Girard, 2005). Si bien en toda comunidad la violencia aparece como comportamiento natural a la tensión de la vida, para que no tenga efectos disolventes, debe ser equilibrada con otro tipo de violencia que oficie de ordenadora: fuerza y reacción en encuentros de violencias. Ambas formas se diferencian en el valor simbólico ordenador que una signa sobre otra: violencia primera del caos y violencia segunda del orden. Girard sugiere que una explicación irracional anida en las relaciones racionales posteriores (Polo López, 2013: 2).

\section{El padre y los modos de la ausencia}

Lo primitivo de la violencia se expresa en formas de agresión y ruptura. Es extrovertida y visible; al identificarse con claridad, se puede contrarrestar. Pero, muy a menudo la violencia también se comporta de manera sutil, resultado de una elaboración sofisticada cuyas consecuencias, por acostumbradas o por imperceptibles, son más hondas y concluyentes. Este segundo modo de 
violencia simbólica está intercalado en las víctimas de Rulfo (Bourdieu, 1999: 65-73).

Violencia física y violencia simbólica se entrecruzan en las figuras paternas. Los padres de Rulfo expresan una carencia de carácter, una limitante que define los vínculos con la descendencia; esa nota constriñe su función y se diversifica en figuras de ausencia. La desaparición en presencia genera un vacío superior aun al del padre muerto. En términos de Aguirre Aguirre para el "escritor mexicano el tema de la ausencia del padre parece sobrepasar el ámbito privado al circular como un elemento medular para el funcionamiento del orden social latifundista que sobrevive después de la Revolución Mexicana" (2016: 168). Esto podría no ser relevante si desde el otro término de la relación, desde el hijo, no hubiera reclamo y dependencia. Pero la respuesta que se necesita y se exige no llega o no es suficiente: "Es algo difícil crecer sabiendo que la cosa de donde podemos agarrarnos para enraizar está muerta", dice el hijo del padre asesinado en Diles que no me maten (El llano, 96).

Las imágenes de padre que desfilan en los textos revelan una violencia por acción o por omisión. Tomaremos dos icónicas: padre autoritario, severo, asesino; padre impotente, pusilánime, pasivo.

El protagonista de la novela, Pedro Páramo, es el padre por antonomasia, que da y quita vida a criterio. Modelo de conducción centralizada, tirano que exige sumisión, Pedro actúa no obstante como el padre buscado y necesitado. No solo es el padre de Juan Preciado, sino, de algún modo, del pueblo de Comala que se le subordina conscientemente porque no entiende otra supervivencia: "Y es de él todo este terrenal. El caso es que nuestras madres nos malparieron en un petate aunque éramos hijos de Pedro Páramo" (PP, 9). Si bien es ejecutor de acciones de explícita violencia (mata a todos los asistentes a una boda) lo es principalmente de violencia simbólica. Sirvan de ejemplo la sumisión económica y la disposición sobre la vida de todos. En el primer caso, ante la muerte de Miguel Páramo y la compra de su viaje al cielo; todo medido 
en términos humanos y a un precio manejado por el caudillo:

-Yo sé que usted lo odiaba, padre. Y con razón. El asesinato de su hermano, que según rumores fue cometido por mi hijo; el caso de su sobrina Ana, violada por él según el juicio de usted; las ofensas y falta de respeto que le tuvo en ocasiones, son motivos que cualquiera puede admitir. Pero olvídese ahora, padre. Considérelo y perdónelo como quizá Dios lo haya perdonado- Puso sobre el reclinatorio un puñado de monedas de oro y se levantó (PP, 29).

Otro ejemplo de violencia pragmática es el matrimonio con Doloritas, madre de Juan Preciado, a quien desposa para aminorar deudas y a la cual nunca le interesa retener. La violencia sobre los afectos como práctica de retención de tierras apenas es un tema considerado impropio de un modelo pre-revolucionario: “-Mañana comenzaremos a arreglar nuestros asuntos. Empezaremos por las Preciados. ¿Dices que a ellas les debemos más?- Sí. Y a las que les hemos pagado menos [...] Y la Lola, quiero decir, doña Dolores, ha quedado como dueña de todo [...] Y es a ella a la que le tenemos que pagar. -Mañana vas a pedir la mano de la Lola" (PP, 39).

La segunda, disposición sobre la vida de sus dependientes, se confirma en la identificación de vida-felicidad, resentimiento-muerte. Mientras dura la efímera dicha del caudillo, el pueblo vive; cuando él sufre, la vida se niega. En cualquier caso, ejerce un poder equivalente al del destino como fuerza suprema: "Enterraron a Susana San Juan y pocos en Comala se enteraron. Allá había feria. Se jugaba a los gallos, se oía la música; los gritos de los borrachos y de las loterías [...] Don Pedro no hablaba. No salía de su cuarto. Juró vengarse de Comala:-Me cruzaré de brazos y Comala se morirá de hambre-Y así lo hizo" (PP. 124).

El mal es infértil. Pedro Páramo, definido como "el marido de mi madre" (PP. 5), o como "un rencor vivo" (PP. 8), el anti-padre, es causa de muerte de la naturaleza. De ahí su mineralización final -Pedro/piedra- al ser ajusticiado por uno de sus hijos. La búsqueda de un padre que se presume muerto -misión 
de Juan Preciado- culmina en el hallazgo de la propia muerte. La integración de Juan al mundo muerto fundado por su padre le revela que hallarlo implica aceptar su violencia dictatorial: su muerte es la entrada al mundo del padre, la muerte es el espacio de recuperación de la identidad. Una justicia cósmica impersonal y severa hace desaparecer la estirpe mal nacida. Inicio y fin violento, sin superación de las fuerzas primitivas de origen.

Otra faz del modelo la presenta Paso del Norte (El llano, 117) donde el padre severo e indiferente corporiza la violencia del desamor, la relación paterno-filial como un frágil vínculo de conveniencias en el cual el débil, el hijo dependiente, reclama mínimas enseñanzas para sobrevivir y el padre desconoce socarronamente su responsabilidad ante la vida dada: “-¿Qué me gané con que usté me criara?, puros trabajos. Nomás me trajo al mundo al averíguatelas como puedas". (El llano, 118). "Pero usté me nació. Y usté tenía que haberme encaminado, no nomás soltarme como caballo entre las milpas" (El llano, 119).

La defensa del padre se sostiene en la certeza de lo ingrato del vínculo, el interés del hijo y la inutilidad de la crianza. Los dos extremos se aíslan y proyectan esterilidad hacia el futuro. Las formas de violencia, antes que rechazo, inducen al reclamo. Se busca al padre en la vida y en la muerte, en la negativa y en la ausencia. El movimiento, dictado por el vínculo, es autodestructivo. Los hijos de padres asesinados buscan venganza sin cerrar el círculo: dejan huérfanos a los descendientes del que los ha dejado huérfanos. La tragedia se sucede. La ley de la sangre combina sufrimientos sin reconciliación.

El otro modo del padre, impotente, pusilánime, pasivo, representa una figura excluida, incapaz de asumir su desafío de crianza ni de educación. La violencia simbólica se confirma en el abandono y en la imposibilidad de superar la apatía, justificada en cierto pasivismo providencialista. El padre en Es que somos muy pobres (El llano, 26) es paradigma de este desaliento; ante la adversidad natural y la pérdida de la pequeña fortuna que amparaba el futuro de la menor de las hijas, se desencadena una tragedia de corrupción que imagina, 
describe por anticipado y ante la cual cede:

La apuración que tienen en mi casa es lo que pueda suceder el día de mañana, ahora que mi hermana Tacha se quedó sin nada. Porque mi papá con muchos trabajos había conseguido a la Serpentina, desde que era una vaquilla, para dársela a mi hermana, con el fin de que ella tuviera un capitalito y no se fuera a ir de piruja como lo hicieron mis otras dos hermanas, las más grandes" [...] "Pero mi papá alega que aquello ya no tiene remedio (El llano, 27).

Luvina muestra un modelo de violencia hecho ley, la ley del llano, rítmica y destructiva. El relato, anticipatorio de Pedro Páramo, articula una irreversible cosmogonía del determinismo sobrenatural, humano, natural: "Sólo quedan los puros viejos y las mujeres solas, o con un marido que anda donde sólo Dios sabe dónde... Vienen de vez en cuando como las tormentas [...] Dejan el costal de bastimento para los viejos y plantan otro hijo en el vientre de sus mujeres, y ya nadie vuelve a saber de ellos hasta el año siguiente, y a veces nunca... Es la costumbre. Allí le dicen la ley, pero es lo mismo" (El llano, 107). El narrador protagonista, mediante la construcción del relato, se distancia de su propia historia, la universaliza para neutralizarla; su presente agónico queda más allá del tiempo y su conciencia permanece igual a sí misma (Foucault, 1980: 7) sin posibilidad, justamente, de autoconciencia.

El modelo de padre desanimado debilita la vida siguiente: si en el primer caso se muere por imposición, en el segundo se muere por abandono; en uno hay fuerza y opresión, en otro hay fragilidad e inercia. Iguales consecuencias para la continuidad de la vida individual y familiar, condenada a la extinción. Junto a la violencia del padre biológico está la del padre histórico, quien transforma el orden social y político, determinándolo a la regresión (Es que somos muy pobres, Paso del Norte). Los hijos que alcanzan el reconocimiento del padre vuelven al punto de partida con resignación y, en tanto sigan viviendo, seguirán en el círculo de su condena. Diles que no me maten (El llano, 89) ejemplifica el espiral de la venganza de sangre en su estado más puro. 


\section{La madre y los modos de la tierra}

Los personajes femeninos se desenvuelven entre violencia física y simbólica; en principio, las mujeres se presentan pasivas y secundarias, excusa de la expansión masculina de la fuerza -son objeto de rapto, violación, abandono; pero, el sufrimiento acentúa su valor dramático (Ramírez, 2008: 62) convirtiéndolas luego en influyentes y relevantes.

Lo femenino asume una doble relación con la violencia: es autora indirecta o es restauradora de lo violentado. La mujer-madre expande la violencia al exigir reparación por los abusos sufridos; ejemplo contundente es la Doloritas de Pedro Páramo, que empuja la búsqueda. Inicia al hijo en un viaje de identificación a través de la venganza. La exhortación inicial de Doloritas: "El olvido en que nos tuvo, hijo, cóbraselo caro" (PP, 5) se transforma pocas páginas después en: "El abandono en que nos tuvo, mi hijo, cóbraselo caro" (PP, 22). Las mujeres saben del pasado, callan o cuentan oportunamente, esperan y amasan, y así movilizan la violencia en los otros. La madre gesta fuerzas, como movimientos telúricos que, imperceptibles, se forman en lo oscuro del resentimiento y alteran la vida.

El otro modelo de mujer, la joven esposa, es el de Natalia en Talpa, energía indirecta que lleva a su esposo a la muerte, desenfrenada como la naturaleza; junto con el desastre, también acarrea la conciencia de culpa: "Nunca había sentido que fuera más lenta y violenta la vida [...] Los ojos seguían la polvareda; daban en el polvo como si tropezaran contra algo que no se podía traspasar. Y el cielo siempre gris, como una mancha gris y pesada que nos aplastaba a todos desde arriba" (El llano, 55).

En semejanza, la Felipa y la Madrina de Macario, la Berenjena y la Arremangada de Acuérdate, mujeres que hacen de su femineidad una herramienta de violencia, en especial al denigrar la función materna. Semejantes conductas muestran las madres reales y posibles de Juan Preciado 
en Pedro Páramo quienes lo guían hacia la muerte. Eduviges recuerda y presenta; Damiana Cisneros y la hermana de Donis salen a expresar desgracias fantasmagóricas; Dorotea muestra y entiende a Susana San Juan. La presencia de las mujeres es aclaración y acercamiento de la propia muerte. La muerte es femenina. La pasividad de las mujeres de Comala, almas en pena que aparecen y se repiten doliéndose, es sin embargo demostrativa y activa: demostrativa porque ejerce una denuncia sobre el furor de Pedro Páramo, que fue sobre la tierra tan injusto como sobre las mujeres. Activa, porque genera venganza y más dolor. Así, Susana San Juan, quien está "simbólicamente muerta" al llegar Comala (Aguirre Aguirre, 2016: 171), causará la destrucción del pueblo, a través del rencor de Pedro.

También, con actitud mansa, la madre es asimilable al carácter de la tierra que siempre sostiene; carga con el reclamo de la naturaleza sufriente, representando a todos los débiles, a los marginados, a los que no tienen voz, como en el mitologema de la Llorona (Martos García, 2015: 194). Permanece impasible, resignada, mientras el hombre viaja hacia lo otro; ya sea padre o hijo, el fundador se mueve en el tiempo para hacer la historia, acaso el relato. La madre que es la que continúa, como la tierra ajada, la guardiana de la memoria: "Sólo quedan los puros viejos y las mujeres solas, o con un marido que anda donde sólo Dios sabe dónde..." (El llano, 107).

La mujer-madre nutre al hijo contra toda esperanza, lo acoge con lo que no tiene para darle continuidad. Sufre la violencia del hombre y de la naturaleza, así como la de su propia condición estanca. Persevera en la anti-vida. El hombre vuelve a pasar sobre la tierra, la germina y la abandona; su peregrinar deja hijos que repetirán el círculo sin trascenderlo. Pero la mujer, en el seno de la violencia, retiene la vida. El recuerdo de la buena madre es suficiente para que el padre, aún contra su voluntad, proteja la vida del hijo criminal en No oyes ladrar los perros: "Me acuerdo cuando naciste [...] Despertabas con hambre y comías para volver a dormirte. Y tu madre te daba agua, porque ya te habías 
acabado la leche de ella [...] Tu madre, que descanse en paz, quería que te criaras fuerte. Creía que cuando tú crecieras irías a ser su sostén. No te tuvo más que a ti” (El llano, 133).

De modo semejante, en El llano en llamas las mujeres quedan abandonadas y están solas con los hijos; los hombres son marginales de la ley y la continuidad de la vida no pasa por ellos. Esas mujeres cercanas a delincuentes no se pervierten y contribuyen al arrepentimiento: “-¡Pichón, te estoy esperando a ti! -me dijo-. Te he estado esperando desde hace mucho tiempo. Yo entonces pensé que me esperaba para matarme. Allá como entre sueños me acordé de quién era ella [...]-Tengo un hijo tuyo -me dijo después-. Allí está” (El llano, 86-87). Más aún, Pedro Zamora es el ejemplo de las mayores amenazas y malhechor famoso, cuya historia de crímenes se cerrará cuando caiga por entregarse a una mujer: como una redención, el mismo amor que lo hace morir, lo eleva: "Dicen que se fue a México detrás de una mujer y que por allá lo mataron" (El llano, 86).

En la relación padre/madre/hijo se confirman constantes de violencia atemperadas por gestos de bondad que sostienen el aletargamiento de la vida, pero no su mejora: la familia sufre y se desmembra (Talpa, Paso del Norte, No oyes ladrar los perros), no se llega a formar o apenas se sostiene (Acuérdate, El llano en llamas), se declara impotente ante las circunstancias (Es que somos muy pobres, Luvina); queda destruida (El hombre, Diles que no me maten) o invalidada (Macario, La herencia de Matilde Arcángel, Anacleto Morones).

La distancia del padre excluye y condena a la madre; la exclusión de la madre clausura la continuidad del padre. Nace así una galería de víctimas: del padre que va y viene sin asentar (Luvina, El día del derrumbe), del que es violador y asesino (El llano en llamas, El hombre) del que genera monstruos (Anacleto Morones) o idiotas (Macario); los hijos de la tierra, atados a estos progenitores, son todos condenados a alguna forma de violencia. Pero, fatalmente, esa unión imperfecta es la única real; ese padre, impetuoso y cruel 
o atemorizado y sumiso, junto a esa madre, seca y sufrida como la tierra que habita, son el conducto vital posible. De la tierra fecundada por ese padre, nace este hombre que vive en la historia. Rulfo ubica el mitologema del padre en el antes del tiempo, donde se origina la violencia, como condición de los hombres de ahora; ese principio, por mítico, es intocable y es determinante del presente. Estos hombres son los hijos de aquéllos: con esta afirmación justifica la vigencia de sus paradigmas: violencia física y violencia simbólica.

\section{La autoridad y modos de la ley}

La integración coherente de la violencia en el universo rulfiano (Forgues, 1987: 34) también se verifica en las relaciones sociales, sostenidas por intimidación y terror. La marginalidad cultural, social e histórica es la nota común a las comunidades. Sus habitantes carecen de educación formal, no hay progreso entre generaciones, ni aspiraciones distintivas. Aunque coexisten con los grandes procesos de cambio, no son sus actores sino sus víctimas, herramientas de fuerzas a veces revolucionarias, a veces represoras. Es el caso de Pedro Páramo, quien hace una parodia de la revolución.

Como las instituciones ilustradas, cuya misión es el cuidado de un orden, revelan su fracaso, las comunidades desamparadas se organizan sustituyendo jerarquías y estableciendo relaciones primigenias de fuerza, de dominio y de distribución arbitraria de bienes materiales y de bienes simbólicos, prestigio, influencia, pertenencia (Avechuco, 2010: 5). Así, a contraluz de los beneficios de la civilización, la violencia es lenguaje universal, ya para establecer autoridad -quién manda o quién obedece- ya para comunicar vínculos -quién es padre o quién es hijo- ya para equilibrar las relaciones comunitarias-quién se desordenó o quién debe ordenar. Tal lenguaje queda dentro del espacio arriesgado y provisorio de la marginalidad.

Acuérdate presenta dos rupturas en el orden de las relaciones comunitarias, ambas propiciadas por el mismo personaje: quien roba a su 
propia gente, hermana en miseria, quien transgrede los vínculos cometiendo incesto, y quien, luego de ser desterrado, vuelve contra los suyos investido del poder oficial para cobrar venganza. El personaje no se convierte a la legalidad; la aplica para avalar su maldad: "Lo cierto es que no lo volvimos a ver sino cuando apareció de vuelta por aquí convertido en policía. Siempre estaba en la plaza de armas, sentado en una banca con la carabina entre las piernas y mirando con mucho odio a todos" (El llano, 128).

En La cuesta de las Comadres el protagonista se resiste con paulatina conciencia a las muestras residuales del caciquismo, poniendo en suspenso las intenciones de la revolución. Los hermanos Torrico detentan el poder del terror, rompen los límites, se apropian de los frutos del trabajo, despojan de la tierra. La acción sufrida produce reacción y llega el equilibrio por contrapeso de violencia. El miedo, que antes permitió la acción perversa, revierte en ajusticiamiento extremo: "A Remigio Torrico yo lo maté. Ya para entonces quedaba poca gente entre los ranchos [...] Creyeron seguramente que el año siguiente sería lo mismo y parece que ya no se sintieron con ganas de seguir soportando las calamidades del tiempo todos los años y la calamidad de los Torricos todo el tiempo" (El llano, 18).

El orden impuesto por las relaciones horizontales, que funcionan mediante desplazamiento de roles, se combina con alguna forma de autoridad vertical que somete a la comunidad. Enfrentado con los protagonistas hay un gran personaje colectivo (gobernante, hacendado, tirano, caudillo, soldado, perfiles mutantes del mismo "padre") que condensa las fuerzas de dominio, no deja hablar, ni escucha, no permite que avance la historia. Como sembrador del miedo, debilita los espacios de libertad y extiende el silencio simbólico de hombres y mujeres. Miedo, esclavitud y silencio se suceden; así en Nos han dado la tierra: "No decimos lo que pensamos. Hace ya tiempo que se nos acabaron las ganas de hablar" (El llano, 8). La autoridad, lejos de ejercer una función ordenadora o educativa -ejemplaridad del orden político- oficia 
de enemigo interno; su arma sutil es una infalible burocracia, eje de violencia simbólica. Como un mal padre, el estado y sus fuerzas se convierten en contraejemplo (Nos han dado la tierra, El día del derrumbe). El estado ridiculiza las energías de progreso que debería representar: “[...] llegó el gobernador; venía a ver qué ayuda podía prestar con su presencia. Todos ustedes saben que nomás con que se presente el gobernador, con tal de que la gente lo mire, todo se queda arreglado [...] En viniendo él, todo se arregla, y la gente, aunque se le haya caído la casa encima, queda muy contento con haberlo conocido" (El llano, 136). En visión paródica, el estado/poder se adueña de las palabras y abusa de ellas, gracias a la ignorancia promovida en el pueblo. El discurso político se arma como mofa de una retórica vulgarizada, ante un pueblo confundido por la presencia casi sagrada -y entonces, intocable- del poder y por la costumbre del alcohol; así lo muestra El día del derrumbe:

-Conciudadanos -dijo- [...] Ante esta tierra que visité como anónimo compañero de un candidato a la Presidencia, cooperador omnímodo de un hombre representativo, cuya honradez no ha estado nunca desligada del contexto de sus manifestaciones políticas [...] firme glosa de principios democráticos en el supremo vínculo de unión con el pueblo, aunando a la austeridad de que ha dado muestras la síntesis evidente de idealismo revolucionario nunca hasta ahora pleno de realizaciones y de certidumbre (El llano, 139).

El discurso de la historia debe confirmarse con la toma de distancia canónica entre el narrador y lo narrado (Barthes, 1970: 35-ss); el humor establece esa distancia, potencia los hechos y los hace más verosímiles.

Como la autoridad normalizadora es incapaz de cumplir su deber y solo somete y se burla, las relaciones comunitarias se quiebran en doble dirección: ya desordenadas horizontalmente, tampoco pueden salvarse verticalmente. Aunque olvidados, esos seres siguen ahí; frente a un estado disfrazado y un hombre distraído, la mujer da a luz sola y sin protección (El día del derrumbe).

Rulfo separa el espacio de la historia del espacio de la conciencia. Al elaborar ficciones sobre conflictos reales, se ubica en la frontera del relato 
historiográfico y del literario; del mismo modo que en el narrador-creador, el historiador no copia o reproduce lo sucedido, sino que ofrece una representación (Pizarro Cortés, Santos Herceg, 2014: 239) la cual es más interpretativa que descriptiva. Si bien los personajes se mueven en circunstancias concretas de la historia política y social mexicana, las ignoran. No perciben la culpa de ancestros o instituciones, aunque padecen la violencia que brota de ellos; en tanto víctimas cargan la culpa y buscan redención, aun con la sospecha de que no hay purgatorio para ellos. En El hombre el desorden social del crimen requiere del equilibrio siempre pendiente por parte de la justicia; en su lugar, la violencia se reimpone a través de la figura sustituta del chivo expiatorio: un licenciado anónimo presiona para hallar "un culpable", no "al culpable": “-¿Y dice usted que me va a meter en la cárcel por esconder ese individuo? Ni que yo fuera el que mató a la familia esa. Yo sólo vengo a decirle que allí en un charco del río está un difunto. Y Usted me alega que desde cuándo y cómo es y de qué modo es ese difunto. Y ora que yo se lo digo, salgo encubridor. Pos ora sí" (El llano, 38). Igualmente, en La noche que lo dejaron solo los representantes de la legalidad son armazón ineficiente y paródico: “-Estamos esperando que llegue el otro. Dicen que eran tres, así que tienen que ser tres [...] Mi mayor dice que si no viene de hoy a mañana, acabalamos con el primero que pase y así se cumplirán las órdenes" (El llano, 114-115).

Tanto como los representantes del estado se degradan incurriendo en variadas formas de violencia, la iglesia como institución también se deshonra. Ejemplificaremos tres formas claras: la ausencia de lo divino sumido en la manipulación del símbolo; la hipocresía del ministerio; la superstición y vulgarización. La dimensión religiosa queda excluida y mimetizada en reciprocidad con el poder.

Tanto en Talpa como en Macario el valor de la redención está medido por intereses humanos (representados en Natalia y la Madrina), el camino de salvación descripto como vía de terror (para los infelices de Tanilo y Macario) y 
la fe menoscabada por el imperativo de la supervivencia (Felipa). El miedo y las relaciones familiares quebradas ponen en sintonía a los protagonistas de ambas historias. El peregrinar forzoso de Tanilo y el día circular de Macario se igualan en su retroceso: ambos tienen negado el futuro, se paralizan en la repetición en espera de la muerte total del infierno; ambos intentan, independientemente de su conciencia, sustraerse de la culpa preexistente. La fe denigrada arrasa los vínculos familiares y aplasta al hombre en busca de su salvación. Dice Macario: "A veces no le tengo tanto miedo al Infierno. Pero a veces sí. Luego me gusta darme mis buenos sustos con eso de que me voy a ir al Infierno cualquier día de estos, por tener la cabeza tan dura y por gustarme dar de cabezazos contra lo primero que encuentro" (El llano, 63).

Alignorarse el núcleo divino de la fe, la religión se suma a los instrumentos de violencia, negando misericordia y promesa de vida eterna y convirtiéndose en mero anuncio de condena: "Yo sé ahora que Natalia está arrepentida de lo que pasó. Y yo también lo estoy; pero eso no nos salvará del remordimiento ni nos dará ninguna paz ya nunca" (El llano, 51). La vivencia de lo sagrado -en el rito, en la peregrinación, en los sacramentos- en lugar de aportar esperanza queda al servicio de repeticiones obligadas, sin capacidad redentora: "Felipa dice, cuando tiene ganas de estar conmigo, que ella le contará al Señor todos mis pecados. Que irá al Cielo muy pronto y platicará con Él pidiéndole que me perdone, para que yo no me preocupe más [...] Eso dice Felipa. Por eso yo la quiero tanto" (El llano, 64).

La hipocresía del ministerio, como duda íntima y contradicción objetiva, se expresa con el padre Rentería de Pedro Páramo. La violencia espiritual que ejerce duplica el plano material -tierra-mujeres-revolución- sobre el que actúa Pedro. Abandona a sus fieles, los manipula y compromete su mediación entre mundos: "El padre Rentería recogió las monedas una por una y se acercó al altar. -Son tuyas-dijo- Él puede comprar la salvación. Tú sabes si éste es el precio" (PP, 29). Rentería muestra el cruce irregular de culpa/perdón, miedo/ 
violencia. Forma parte, sin sobresalir moralmente, del gran purgatorio que simboliza toda Comala; su vida es semejante a un purgar perpetuo, en tanto es de los pocos personajes que no muere en la novela. Otro cura, vecino y, por ende, no contaminado por el vicio del pueblo, se lo dice al par que le niega la absolución: "-Ese hombre de quien no quieres mencionar su nombre ha despedazado su iglesia y tú se lo has consentido ¿Qué se puede esperar ya de ti, padre?" (PP. 75).

La muestra religiosa que Rulfo ofrece, dominada por la superstición y la subordinación al poder, desampara a los fieles y vacía el ritual privándolo del componente esencial de la misericordia. Ejemplo grotesco de vulgarización de lo sagrado en nombre del más mezquino mercantilismo es Anacleto Morones, relato de la inversión del sentimiento religioso y de falsificación de verdades genuinas: “-¿Desde cuándo no te confiesas?- ¡Uh!, desde hace como quince años. Desde que me iban a fusilar los cristeros. Me pusieron una carabina en la espalda y me hincaron delante de cura y dije allí hasta lo que no había hecho. Entonces me confesé hasta por adelantado" (El llano, 161). Todos los personajes del relato están envilecidos, los presentes, los recordados y hasta los santificados. El protagonista en ausencia, Anacleto Morones, un estafador y corruptor inescrupuloso, tanto como el protagonista en presencia, Lucas Lucatero, asesino y padre de monstruos, son ejemplos nítidos. Todos están llamados a exterminarse.

Una violencia repetida y mudable ejerce el movimiento axial que sostiene vida-muerte-vida, mientras margina a los personajes del genuino orden familiar, comunitario y trascendente.

\section{Conclusiones}

La obra de Rulfo puede leerse al modo de las antiguas cosmogonías, en las cuales el hombre está ligado a un ritmo universal que lo excede, en un entorno 
que no puede objetivar, perplejo ante las encrucijadas y fundamentalmente ajeno a la evolución histórica. Es el hombre en pleno estadio de reiteración mítica. En ese horizonte, la violencia es la fuerza dominante, pre-histórica, dada antes de toda cultura y activa en el interior de los formatos pretendidamente civilizados; no hay argumento que la cuestione, capacidad para detenerla, ni energía para cambiarla. Antes bien, se la acepta y normaliza al punto de venerarla como el modo de realización de la vida.

El autor no propone una explicación de la violencia a la luz de la dicotomía civilización/barbarie; su racionalización, es decir, su inclusión en un sistema lógico, la definiría como un primitivismo que debe superarse en las sociedades organizadas. Por el contrario, en el contradiscurso mítico de Rulfo, la violencia es el principio de orden y eliminarla de los vínculos existenciales equivaldría a hacerlos desaparecer. Lejos de ofrecer una advertencia moralizante, los relatos iluminan la matriz de la violencia y Rulfo, como poeta trágico, anuncia su fatal permanencia y su invariable repetición. Lo natural no puede ser erradicado.

Afirmada la unidad primigenia de vida y violencia, los espacios de la civilización -superpuesta en la cronología, mas nunca asimilada en la culturaespacios tales como la filosofía, la política o el derecho, quedan sostenidos formalmente sobre estructuras irracionales: el accionar de los responsables de la ley, de los representantes del estado o de las instituciones jerárquicas de la sociedad, son mutaciones de la misma violencia básica.

Si aceptamos con Girard, que la violencia mítica es "fundadora de una nueva verdad" (2005:92), la cosmogonía pre-ilustrada de Rulfo sugiere que solo sobrevolando las categorías racionalistas nos acercaríamos a la comprensión de su mundo mexicano.

\section{Referencias}

Aguirre Aguirre, Carlos Sergio (2016). "Sobre espectros y memorias subalternas en "Pedro Páramo" de Juan Rulfo". MILLCAYAC 
- Revista Digital de Ciencias Sociales / Vol. III / No 4, 163-176, Centro de Publicaciones FCPyS, UNCuyo, Mendoza.

Avechuco Cabrera, Daniel (2010). "Los motivos de la rabia: violencia mítica en El Llano en llamas de Juan Rulfo". Espéculo. Revista de estudios literarios, Madrid Universidad Complutense. Disponible en: http://www.ucm.es/info/especulo/numero44/violmiti.html.

Barthes, Roland (1970). Estructuralismo y literatura. Buenos Aires: Nueva Visión.

Benjamin, Walter (2009). "Para una crítica de la violencia". Archivos, 2/3, 425-452.

Bourdieu, Pierre (1999). Intelectuales, politica y poder. Buenos Aires: EU DEBA.

Chang Rodríguez, Raquel y Piler, Malva E. (2015). Voces de Hispanoamérica. Boston: Cengage Learning, 2015.

Cruz Rivero, Juan (1999). Modernidad e industria de la cultura. Instituto Tecnológico y de Estudios Superiores de Monterrey, México: Plaza y Valdés.

Forgues, Roland (1987). Rulfo, la palabra redentora. Barcelona: Puvill Libros.

Foucault, Michel (1980). Microfísica del poder. Madrid: La Piqueta.

Girard, René (2005). La violencia y lo sagrado. Barcelona: Anagrama.

Horkheimer, Max y Adorno, Theodor (1969). Dialéctica de la Ilustración. Buenos Aires: Sur.

Lara, Eliseo (2015). "Las formas de la historia. Del discurso histórico del poder a las expresiones contrahistóricas en América Latina". Universum, 30 (1), 137-151.

Martos García, Alberto y Martos García, Aitana(2015). "Nuevas lecturas de La Llorona: Imaginarios, identidad y discurso parabólico". Universum, $30(2), 179-195$.

Pizarro Cortés, Carolina y Santos Herceg, José (2014). "Del relato maestro a la polifonía historiográfica. Crítica a la historia de la emancipación latinoamericana". Universum, 2 (29), 237-251. 
Polo López, Marco (2013). "La violencia y lo sagrado: la teoría mimética en la filosofía de René, Girard". Jornadas Diálogos: Literatura, Estética y Teología. La libertad del Espíritu, V, Buenos Aires: U.C.A, 17-19. Disponible en: http://bibliotecadigital.uca.edu.ar/repositorio/ ponencias/violencia-sagrado-teoria-mimetica.pdf.

Ramírez, Hugo Hernán (2008). "El personaje femenino en los cuentos de Juan Rulfo". Iberoamericana, 8 (30), 47-63.

Rulfo, Juan (2005). El llano en llamas. México: Ed. RM.

Rulfo, Juan (2005). Pedro Páramo. México: Ed. RM.

Rulfo, Juan (1997). Toda la obra. Edición crítica de Claude Fell. Madrid: ALLCA XX. Colección Archivos. 